\title{
Reading Ability Analysis of Mandarin Language In Pontianak Junior High School VIII Grade Students
}

\author{
Lily Thamrin \\ Mandarin Language Education Study Programme \\ FKIP, Tanjungpura University \\ Pontianak, West Kalimantan, Indonesia \\ lilythamrin1806@gmail.com
}

\author{
Reni Marlina \\ Biology Education Study Programme \\ FKIP, Tanjungpura University \\ Pontianak, West Kalimantan, Indonesia \\ reni.marlina@fkip.untan.ac.id
}

\author{
Yokhebed \\ Biology Education Study Programme \\ FKIP, Tanjungpura University \\ Pontianak, West Kalimantan, Indonesia \\ Yokhebed0405@gmail.com
}

\begin{abstract}
Reading ability is one of the skills in mandarin language. High using of mandarin language leads to mandatory and additional subjects, ranging from kindergarden to vocational schools in Pontianak, West Kalimantan, Indonesia. Indicators of reading mandarin language are measured in the form of vocabulary mastery, pronunciation,and read tone. The method by doing observation, interview, and literature study. The subject of this study is the VIII grade students in Immanuel Junior High School Pontianak. Based on data analysis, it is found that the reading Mandarin ability of VIII grade students in Immanuel Junior High School Pontianak is included in the low category 26 $\%$, medium category $26 \%$ and high category $48 \%$. Further, necessary to develop the media in supporting the reading mandarin ability in school.
\end{abstract}

Keywords—reading; mandarin; ability; language; analysis

\section{INTRODUCTION}

Mandarin has become a widely used language of the World. Currently there are more than 1.3 billion people who regard Mandarins as their mother tongue (United Nations, 2011). China's dominance throughout the country including in the fields of economic, political, military, and cultural development over the last decade is known as the "rising dragon" of the world. Together these four areas play an important role in the world economy, particularly in East Asia. As a result, the importance of Mandarin-language skills has attracted a lot of attention among observers in the world. In addition to China, there are three other areas: Hong Kong, Singapore, Taiwan where Mandarin is considered to be one of the main / official languages. Along with the development of the era, Chinese has become popular in Indonesia, as evidenced by the policy issued of the Ministry of Education (Feng, 2009; Hu \& Commeyras, 2008). Based on statistical data documented by Wen and $\mathrm{Hu}$ (2007), a large number of students studying mandarin languages have been expanding at all levels of education including elementary, secondary, and university levels. In 2007, approximately 850,000 mandarin teachers in Indonesia (Wen \& Hu, 2007), this strengthened the demand for learning Mandarin in Indonesia.

Reading ability in Mandarin involves a complex system of skills related to the visual (ie, emergence of words), orthography (visual word form), phonological, and semantic processing (Chall, 1967). In one of the theory, how to read Mandarin is based on a child spoken language, which has been well developed before formal school begins which is written in mandarin textbooks and then phonologically translated. The meaning of the words written in the mandarin books will be read correctly if the student has the phonological abilities that exist in the spoken language system (Perfetti, 1985). Thus, the child's awareness of a language phonological structure plays an important role in the reading ability development. Since the 1960s, a large number of studies have supported this theory and demonstrated that the child's phonological sensitivity serves as a universal mechanism governing the reading ability in various writing systems (Shankweiler \& Liberman, 1972). Phonological awareness is on several levels, from roughsound units such as syllables to finer sound units such as phonemes represented by letters. Different sound sizes can explain the differential reading ability in Mandarin (Goswami, 1999) thus, the centrality of the phonological sensitivity in learning to read Mandarin is a major factor in mastering mandarin.

Mandarin language is widely studied throughout the world. In addition, we also know that Mandarin is the language with the world's most speakers. In Indonesia, mandarin has been widely studied schools both private schools and public schools. In Pontianak, mandarin lessons begun to be taught from the level of Kindergarten, Elementary School, 
Junior High School, Senior High School and Vocational High School as compulsory or additional subjects. Since 2006, mandarin has been taught in Immanuel Bilngual Class Junior High School. In Mandarin learning there are 4 basic components that must be taught to students that is reading, writing, listening and speaking. Teaching materials used for learning Mandarin at SMP IBC VIII grade Pontianak using the book "Hanyu 7" published by Jinan University Press. The VIII grade of IBC Junior High School has more or less mastered 500 mandarin vocabulary.

Mission of Immanuel Bilingual Class Junior High School is educating students to be academically, physically, mentally, and spiritually qualified human beings and having the ability and passion of learning throughout their lives so as to face change in the global and dynamic era. In support of the mission realization of the school, mandarin is believed can help its students in the face of the increasingly modern era. In Mandarin learning process, the method used to improve the reading ability of junior high school students is very important. Mandarin Lessons also requires a model or learning method is appropriate and fun in the learning process, so it can help students in understanding the information presented in the classroom. In Mandarin learning process the students not only sit idly listening to the teacher explain, but the students also have to be active in the class to practice in daily use so that the language learned can be used in everyday life. One of the learning strategies used to improve students' learning ability is using word cards. In formal schools, students usually learning of mandarin language through several media, such as books, videos, CDs or from Mandarin songs.

Based on a learning process observation in the classroom, mandarin learning at Immanuel junior high school Pontianak has been planned as well as possible based on learning theme, teachers implement the learning in accordance with the planned and done as possible according to the learning stage. But, measurements have not been done in 3 aspects that include vocabulary mastery, pronunciation, and tone read. So the purpose of this research is to identify the ability of Mandarin language of SMP Class VIII Immanuel Pontianak which measured through 3 aspects include vocabulary mastery, pronunciation, and tone which is read.

\section{METHOD}

This study uses descriptive method. This study is intended to raise facts, circumstances, variables, and phenomena that occur when doing by research and presents what it is (Subana and Sudrajat, 2009). Descriptive research is intended to express of students reading ability in Mandarin based on the use of word cards. The subject of this study is the students of SMP VIII grade Immanuel Bilingual Class, academic year 2017/2018 amounted to 27 people. In this study, the techniques to be used in conducting data collection are observation, interview and literature study. Observations made in this study is a participant observation, conducted by 2 observer to see students' reading skills in the learning process. Interview conducted to check back students difficulties experienced in reading is selected from students who categorized low literacy skills. Library study is used in collecting information related to the support of reading skills. The observed aspects of the ability to pronunciation, tone and mastery of vocabulary. Based on observations, data analysis using rating scale to be categorized based on students' reading ability.

TABLE I. CRITERIA OF STUdENT REAding AbILITY

\begin{tabular}{|l|l|l|}
\hline No & Range & Category \\
\hline 1 & $50-69$ & Low \\
\hline 2 & $70-79$ & Medium \\
\hline 3 & $>80$ & High \\
\hline
\end{tabular}

\section{RESUlT AND DISCUSSION}

Based on the reading analysis results, it can be seen that the learning of Mandarin on the material related to the students daily life. Learning is done by using the media card. Students have no trouble reading text on the media card used by students independently, because hanzi and pinyin text on media can be read clearly. This can be seen from the observation with a percentage that can read clearly as much as $81.5 \%$.

The images on the card media used are interesting to observe because they are colorful and clear, so it can improve students' motivation to read the two-language designed Indonesian-Mandarin card. Based on the observations of students of SMP IBC VIII grade shows students using the card media to support Mandarin learning, as well as media cards used also provide a positive impact to students, where the word card media used can make them more understanding in learning.

Based on the observation results also obtained information that the use of media cards can add Mandarin vocabulary students. By increasing the new vocabulary of students, the students will be more interested to read the media card in Indonesian - mandarin language. Based on interview results, students feel very helped by the cards design are made in color, in addition to the media cards used are equipped with pinyin and tone rules, students are interested to learn the word card. By student interested to learn Indonesia - mandarin media card, the skills of reading, writing, and speaking in Mandarin will also grow. In addition, the use of card media makes students become more happy to learn Mandarin, because the media used can give the desired results. The results of students' reading ability can be seen in table 2 below.

TABLE II. READING ABILITY

\begin{tabular}{|l|c|c|c|}
\hline \multirow{2}{*}{$\begin{array}{c}\text { Table } \\
\text { Head }\end{array}$} & \multicolumn{3}{|c|}{ Reading Ability (\%) } \\
\cline { 2 - 4 } & Low & Miedium & High \\
\hline $50-69$ & 26 & & \\
\hline $70-79$ & & 26 & \\
\hline$>80$ & & & 48 \\
\hline
\end{tabular}


The observation result of reading ability in Mandarin gives satisfactory result where the reading ability of students whose value is above 70 is $74 \%$. Based on the results of the students' reading ability analysis, it was found that the pronunciation error when reading the word card of the students of SMP IBC VIII grade Pontianak is at the time of pronouncing the word with the consonant aspiration (送气音 / sòng qì yīn) and the non-aspiration consonant (不送气音 / bù sòng qi $y \overline{1})$, where at the time of reciting the aspiration consonant to be accompanied by the air impulse of the mouth, but pronounced with the sound of a non-aspiration consonant, for example (器官 qi guan) meaning the organ is pronounced into (鸡冠 ji guan) meaning the chicken crown. aspiration student misbehavior of SMP IBC VIII grade Immanuel Pontianak as much as $25,9 \%$.

While the most significant tone errors are on vocabulary ( $一 \mathrm{y} \overline{1})$ and (不 bu). Tone error on vocabulary (一 yi ge) is $74.1 \%$ and tone errors on vocabulary (不会 bu hui) is $66.7 \%$. Where in mandarin there are several tone rules that must be considered as when uttering vocabulary ( $-y \overline{1})$ and

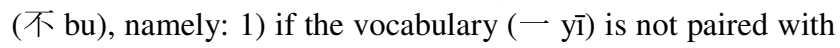
another vocabulary then the vocabulary $(-y \overline{1})$ is still pronounced according to the original tone or at the end of the sentence $(-y \overline{1})$ is also still read after the original tone is the first note. 2) If $y \overline{1}$ is followed by the fourth note, then $y \overline{1}$ becomes the second note. 3) if ( $-\mathrm{y} \overline{\mathbf{1}})$ is followed by one, two, and three tones, then yi turns into four. While the tone rules of the word (不 bu) are: 1) If the vocabulary (不bu) is not paired with another vocabulary then the vocabulary (不bu) remains read after the original tone of the fourth note. 2) When followed the fourth note, then (不 bu) is read into the second note.

Tone errors experienced by the students are due to Indonesians having difficulty in obtaining the chin's tone (Wang, Jungman, and Sereno, 2001). Even though, noted that the reading Mandarin tone is very important to note because reading consonant vowels and tone is the basic thing to be able speak mandarin (Amelia, 2013). The author sees that the cause of the tone error in SMP Immanuel because at the beginning of the lesson, the students have not been taught how to read consonant letters and correct tones first. In addition, the students less diligent practice tone pronunciation and mandarin language lessons are still less time allocation, thus causing many students can not properly pronounce.

In mandarin language, each syllable has a fixed tone. The tone high and low, decreases and rises depend on the vocal cords vibration level. The tone in the mandarin language is not specified only by the tone level, but also by the transition pattern. There are levels, ups and downs, caused by sound changes. For example, neutral tones in the language are interconnected with the sound intensity. The easiest and most effective way of transcribing and recording tones is the tone sound system proposed by Chao (1968). It classifies the pitch tone to five degrees, and dividing the perpendicular line into four part indicating the tone pitch location. Low, middle to lower, middle, upper middle and high notes are shown by the number 1, as illustrated in Figure 1

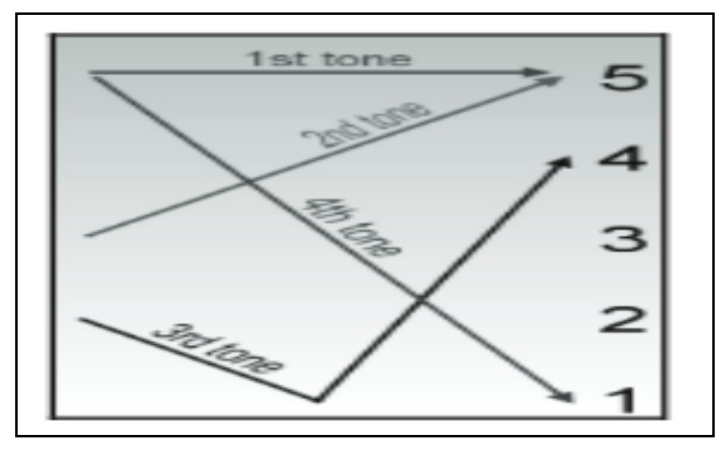

Fig 1. Five (5) Tone Degree in Mandarin (Chao, 2003)

When Indonesian students listen to Mandarin, they often fail to determine which syllable they hear (Zhu, 1997). Two causes of error have been found in determining tone in mandarin:

1. the last syllable is easier to say than the initial syllable

2. tone 2 and 3 are more difficult for students to master

Furthermore, by comparing the ratio of tone errors in pronouncing sentences in mandarin, the initial syllable seems more difficult than the last word entries. Moreover, the subject is quite eager to say the words in the same way as hearing. less error in pronunciation than in tone. We also found several opinion differences between tone errors and mispronunciation.

\section{CONCLUSION}

Based on data analysis, it is found that the reading Mandarin ability of VIII studentsgrade in Junior High School Immanuel Pontianak is included in the low category $26 \%$, moderate category $26 \%$ and high category $48 \%$. Further, necessary to develop the media in supporting the Mandarin ability in school.

\section{References}

Amelia, D. (2013). Latihan Pelafalan Nada dalam Bahasa Cina Mandarin+Audio". Retrieved from: http://www.kesaintblanc.co.id/blog/?p=1445.

Chall, J. S. (1967). Learning to Read: The Great Debate. New York: Fort Worth.

Chao Y. R. (1968). A Grammar of Spoken Chinese. Berkeley: University of California Press.

Chao L. J. (2003). Special Phonetic Instruction in Chinese to Japanese Students. Journal of Yunnan Normal University, 1(3): 66-67.

Feng, A. (2009). Mandarin Education in Asia: Convergence and divergence in policy and practice. AILA Review, $22(1), 85-102$.

Goswami, U. (1999). Learning to Read and Write: A CrossLinguistic Perspective. UK: Cambridge Univ. Press. 
Hu, R. \& Commeyras, M. (2008). A case study: Emergent biliteracy of a5-year-old child with a wordless picture book. Reading Psychology, 29 (1), 1-30.

Perfetti, C. A. (1985). Reading Ability. New York: Oxford Univ. Press.

Shankweiler, D. P. \& Liberman, I. Y. (1972) in Language by Ear and by Eye: The Relationships between Speech and Reading. Journal Child Psychol. Psychiatry. 45, (2). 293-329

Subana,M\& Sudrajat. 2009. Dasar- dasar Penelitian Ilmiah. Bandung: Pustaka Setia.

United Nations. (2011). Population estimates and projections sections. Retrieved from: http://esa.un.org/ unpd/wpp/country-profiles/country-profiles_1.htm.

Wen, Q. F., \& Hu, W. Z. (2007). History and policy of Mandarin education. Seoul: Asia TEFL

Wu Z.J.\& Lin M.Z. (1989). An Outline of Experimental Phonetics. Peking: High Education Press.

Zhu C. (1997). The Strategies of Foreign Students for the Phonetic Learning in Chinese. Peking: Beijing Language and Culture University Press. 